\title{
Reactive Extrusion of Polyethylene Terephthalate Waste and Investigation of Its Thermal and Mechanical Properties after Treatment
}

\author{
Mahmoud A. Mohsin, ${ }^{1}$ Tahir Abdulrehman, ${ }^{2}$ and Yousef Haik ${ }^{2}$ \\ ${ }^{1}$ Department of Chemistry, University of Sharjah, P.O. Box 27272, Sharjah, UAE \\ ${ }^{2}$ College of Science and Engineering, Hamad Bin Khalifa University, P.O. Box 34110, Doha, Qatar \\ Correspondence should be addressed to Mahmoud A. Mohsin; mmohsin@sharjah.ac.ae
}

Received 6 October 2017; Accepted 6 November 2017; Published 23 November 2017

Academic Editor: Jose C. Merchuk

Copyright (C) 2017 Mahmoud A. Mohsin et al. This is an open access article distributed under the Creative Commons Attribution License, which permits unrestricted use, distribution, and reproduction in any medium, provided the original work is properly cited.

\begin{abstract}
This study investigates treating polyethylene terephthalate (PET) waste water bottles with different mass of ethylene glycol (EG) using reactive extrusion technique at a temperature of $260^{\circ} \mathrm{C}$. The study puts emphases on evaluating the thermal, mechanical, and chemical characteristics of the treated polyethylene terephthalate. The properties of the treated PET from the extruder were analyzed using FT-IR, TGA, DSC, and nanoindentation. The melt flow indexes (MFI) of both treated and untreated PET were also measured and compared. Thermal properties such as melting temperature $\left(T_{m}\right)$ for treating PET showed an inversely proportional behavior with the EG concentrations. The FT-IR analysis was used to investigate the formation of new linkages like hydrogen bonds between PET and EG due to the hydroxyl and carbonyl groups. Nanoindentation results revealed that both the mechanical characteristics, elastic modulus and hardness, decrease with increasing EG concentration. On the other hand, the melt flow index of treated PET exhibited an increase with increasing EG concentration in the PET matrix.
\end{abstract}

\section{Introduction}

Synthetic polymers have undergone remarkable growth in terms of diversity, quality, and production volume in recent years [1]. The main difference between the two classes of polymers, namely, natural and synthetic polymers, is that the former are biologically or environmentally degradable, which makes them less durable and have high production cost, whereas the latter last considerably longer in all applications, being almost nonbiodegradable under normal circumstances. The nonbiodegradability of synthetic polymers has triggered a major unease for environmentalists in terms of polymer waste management [2]. In recent years, recycling of synthetic polymers has caught the attention of many research groups, for two major motives: to minimize the ever growing volume of polymer waste and to create value-added items from low cost resources by transforming synthetic polymeric waste into beneficial and useful items having similar properties to virgin materials [3-6].
PET is considered as a multipurpose polymer used for the manufacture of products which differ extensively in their properties and thus differ in their use. Owing to its extensive use over the years, PET is considered as one of the most important polymers in the present world $[7,8]$. PET is semicrystalline, transparent, thermoplastic polyester. It has good tensile strength, chemical resistance, and suitable thermal stability. Huge quantities of PET are used in the production of food packaging materials and water bottles $[9,10]$. With the enormous development and usage of PET, a large fraction of PET gets added to the waste system on a yearly basis. The demand for nonbiodegradable PET in various applications has been increasing at an alarming rate $[11,12]$. Although PET is not hazardous, many factors contribute to the accumulation of PET in the environment and this necessitates serious attention to recycling as the accumulation has become a global environmental issue $[2$, $13,14]$. The recycling of PET through chemical methods $[10,15-18]$, especially depolymerization or lysis of PET using 
solvents and ionic liquids, has gained considerable interest as it can help in the synthesis of different kinds of end products. Depolymerization of PET can be achieved by hydrolysis using water [19] or lysis using alcohol [20] (methanolysis using methanol) [21, 22] or amines [23] or acids [24]. The most established or commercialized processes for the depolymerization of PET are glycolysis, hydrolysis, and methanolysis [5]. The depolymerization of PET can also be classified based on the type of catalyst or ionic liquids or supercritical conditions used in the process [25].

Glycolysis is the process where glycols like ethylene glycol (EG) are used in the lysis of PET [26] and glycolysis also has applications in the formulation of resins comprising unsaturated polyesters. Ethylene glycol is used in the reduction of metal salts to metals $[27,28]$ and is a precursor to polyesters, in addition to its various other applications [27]. The rate of PET glycolysis is found to be of second order in terms of EG concentration [29]. From the glycolysis reaction, the monomer bis(2-hydroxyethyl) terephthalate (BHET) is the main product and the rate of reaction is dependent on various factors which include temperature, pressure, ethylene glycol concentration, and the catalyst involved. For a recycling process to be desirable, it should be effective in terms of energy consumption and expenses related to processing. Glycolysis is usually carried out in boiling ethylene glycol [30] in the presence of catalysts like zinc acetate [31] or lead acetate [16]. The use of such catalysts in large scale may cause pollution due to their toxic nature [5]. The properties of PET can be modulated by treating it with suitable reagents or dry processes for use in various applications $[32,33]$. The wettability or hydrophilic property of PET was enhanced using two dry processes, namely, atmospheric pressure plasma and ultraviolet excimer light [32]. Reactive extrusion was used to modify the rheological and mechanical properties of PET by treating with acrylic epoxy resin as the chain extender [33]. Composites prepared from melt blending of PET and nanoclay were found to have enhanced Young's modulus compared to PET and also prevented the migration of terephthalic acid into yoghurt drinks which were maintained in PET-nanoclay composites [34]. Antimicrobial PET fabric was synthesized from PET$\mathrm{MgO}$ composites that were produced by the melting, mixing, and extrusion of PET and magnesium oxide nanoparticles [35]. Composites of PET with microencapsulated carbon microspheres (MCMSs) were prepared by melt blending and these composites were found to have good flame retarding and mechanical properties $[36,37]$. Hence, the properties of PET can be enhanced by melting blending or extrusion with certain characteristic materials.

Coprocessing is another method of using plastic wastes as raw material or as a source of energy or to replace both natural mineral resources and fossil fuels such as petroleum, coal, and gas in energy intensive industries such as cement, steel, and power generation [38-40].

In this work, PET was treated with $0,0.4,0.6,1,1.4$, and 2 grams of EG using a single screw extruder at the temperature of $260^{\circ} \mathrm{C}$. The effect of different mass of EG on PET degradation was investigated. The chemical, thermal, and mechanical properties of the treated PET were investigated.

\section{Experimental}

2.1. Materials and Methods. The collected PET waste bottles were cleaned, dried, and shredded into small pieces. Ethylene glycol (99.5\% (G.C) minimum assay, Panreac, Spain) was used for the treatment of PET. A single screw extruder (HAAKE POLYLAB QC, Thermo Scientific, Germany) was used for the reactive processing of PET with different mass of EG. Electrical Grinder (Geepas Industrial Co. Ltd., China) was used to mill the extruded PET and convert it into powder for further analysis and melt flow index measurements.

2.2. Treated PET Sample Preparation. The preparation procedure was divided into two parts. In the first part, $20 \mathrm{~g}$ sample of the shredded PET waste was weighed. Then it was placed in the hopper of the extruder, after the extruder barrel was heated to the temperature of $260^{\circ} \mathrm{C}$. The PET was maintained in the barrel at $260^{\circ} \mathrm{C}$ with very low screw speed for 15 minutes to achieve a complete melting of the PET. The screw speed of the extruder was adjusted to $10 \mathrm{rpm}$ in order to obtain a homogenous spread of melted PET in the extruder barrel. Then the speed of the screw was increased to $50 \mathrm{rpm}$ to extrude the entire PET from the extruder. In the second part of the experiment, a mixture of PET and EG was prepared. A $20 \mathrm{~g}$ sample of PET was placed in a flask, and then $0.4 \mathrm{~g}$ of EG was added. The mixture was placed inside the extruder at $260^{\circ} \mathrm{C}$ for $15 \mathrm{~min}$ at $10 \mathrm{rpm}$ in order to obtain a homogenous mixture. The speed of the screw was increased to $50 \mathrm{rpm}$ to extrude the treated PET from the extruder. The same procedure was repeated to analyze the effect of $0.6 \mathrm{~g}, 1 \mathrm{~g}$, $1.4 \mathrm{~g}$, and $2 \mathrm{~g}$ of EG on the PET. Each treated PET sample was kept at room temperature in sealed plastic bags.

2.3. Fourier Transform Infrared Spectroscopy (FT-IR). Fourier transform infrared spectrometer (MAGNA-IR 560 Spectrometer, Thermo Nicolet Corporation) was used to identify the functional groups of the extruded PET treated with different mass of EG. The extruded PET was grinded to a fine powder and a few milligrams of the sample was grinded with dry $\mathrm{KBr}$ to a very fine powder. This powder was then compressed into a thin disc. First, the FT-IR instrument was calibrated by scanning the background. Then, the $\mathrm{KBr}$ disc was placed in the sample holder which was inserted into the FT-IR spectrometer for analysis. The infrared transmission spectral results of the samples were attained at room temperature in the wavenumber range $4000-400 \mathrm{~cm}^{-1}$ using 32 scans with a resolution of $2 \mathrm{~cm}^{-1}$.

2.4. Thermogravimetric Analysis (TGA). The TGA analysis of the treated PET was carried out utilizing a Thermogravimetric Analyzer (Q50, TA Instruments). Samples of $15 \mathrm{mg}$ weight were taken in the sample pan. Then loaded sample pan was placed in the balance suspended inside the furnace tube, which was then heated from room temperature to $600^{\circ} \mathrm{C}$ at the rate of $10^{\circ} \mathrm{Cmin}^{-1}$ in $\mathrm{N}_{2}$ atmosphere. The obtained TGA measurements were evaluated with the software, TA Universal Analysis 2000 (TA Instruments). 
2.5. Differential Scanning Calorimetry (DSC). The DSC analysis of the treated PET was performed with a Differential Scanning Calorimeter (Q200, TA Instruments). The treated PET sample $(\sim 5 \mathrm{mg})$ was placed in an aluminum $T_{\text {zero }}$ sample pan. Then the sample was sealed with aluminum $T_{\text {zero }}$ lid using a pressing machine. The sealed pan was placed in the DSC device, where the reference cell was an empty sealed aluminum pan. All samples were subjected to heating from ambient conditions to $400^{\circ} \mathrm{C}$ at a rate of $10^{\circ} \mathrm{Cmin}^{-1}$ in nitrogen atmosphere. The DSC graphs obtained were evaluated with the software, TA Universal Analysis 2000 (TA Instruments). The melting temperature $\left(T_{m}\right)$ was determined from the DSC thermogram as the pinnacle temperature value of the endothermic outcome.

2.6. Nanoindentation. The mechanical properties of the treated PET were obtained using nanoindentation, (NanoTest, Micro Materials, UK), using a Berkovich diamond indenter. The indentations were made by applying a maximum load of $10 \mathrm{mN}$ at a constant rate of displacement of $0.05 \mathrm{mNs}^{-1}$. On attaining the maximum load, the indenter was removed from the surface of the sample at the same rate of $0.05 \mathrm{mNs}^{-1}$ till the indenter was totally withdrawn from the sample. The purpose of maintaining a uniform displacement rate for indentation of the samples is to prevent hardening effects due to strain on the measurements. A total of five indents were made on each sample with a distance of $50 \mu \mathrm{m}$ between the indentations to prevent interactions.

The load-depth data from the indentations was used to determine the hardness $(H)$ and reduced moduli $(E)$ of the samples.

The deformation associated with both elastic and plastic behavior occurs during the indentation of the specimen, but as a result of unloading of the indenter only the elastic portion is recovered.

The hardness $(H)$ value as a result of indentation can be defined as in

$$
H=\frac{P_{\max }}{A}=\frac{P_{\max }}{24.5 h_{c}^{2}} .
$$

The load value determined at the maximum level or depth of penetration $(h)$ during an indentation cycle is represented by $P_{\max }$, whereas " $A$ " represents the projected contact area and $h_{c}$ denotes the depth of contact during the indentation. The value of $h_{c}$ can be calculated by means of

$$
h_{c}=\frac{h-0.75 P_{\max }}{S} .
$$

$S$ is derived from the early or initial region of the unloading curve and denotes the slope $(d p / d h)$ when $h=h_{\max }$. The value 0.75 in (2) is a constant and is mainly dependent on the geometry of the indenter.

The initial unloading contact stiffness $(S)$ can be used to determine the elastic modulus of the sample. The equation for the relationship between contact stiffness, reduced modulus, and contact area is represented by

$$
S=2 \beta E_{r}\left(\frac{A}{\pi}\right)^{1 / 2} .
$$

The constant $\beta$ is dependent on the indenter geometry. For a Berkovich indenter, $\beta$ has a value of 1.034 . The reduced elastic modulus is represented by $E_{r}$. The reduced modulus takes into consideration the elastic deformation of not only the specimen but also the indenter. The reduced modulus, $E_{r}$, is evaluated by determining the contact stiffness $(S)$ and contact area $(A)$ from the load-displacement graph obtained by the indentation process. The elastic modulus $\left(E_{s}\right)$ of the sample is calculated as shown in

$$
E_{s}=\left(1-v_{s}^{2}\right)\left\lceil\frac{1}{E_{r}}-\frac{\left(1-v_{i}^{2}\right)}{E_{i}}\right]^{-1}
$$

Poisson's ratios of the specimen and indenter are represented by $v_{s}$ and $v_{i}$, respectively. Poisson's ratio for the indenter has the value of 0.07. $E_{i}$ represents the modulus of the Berkovich diamond indenter which has a value of $1141 \mathrm{GPa}$. Poisson's ratio $v_{s}$ for the specimen was estimated to be 0.35 which is the value for semicrystalline polymeric materials. This value was used for all calculations.

2.7. Melt Flow Index (MFI). The melt flow index for the treated PET was performed using XRL-400A/B/C series, Material Flow Velocity Machine (Chengde Jingmi Testing Machine Co., Ltd., China). The melt flow index apparatus consists of two testing modes: displacement testing mode and time testing mode. The displacement testing mode measures the flow index as the distance covered by a certain tested sample, expressed as grams/centimeter. Alternatively, the time testing mode measures the time needed to cut a certain amount from the tested sample, expressed as gram/10 minutes. The latter mode was selected for measuring the melt flow index. The treated and untreated PET samples were grinded and converted into powder using a grinder. Then the samples were weighed and place into the MFI instrument for testing. The parameters (cutting time, temperature, and load) were adjusted by performing several tests on the samples in order to optimize the testing parameters. The samples were heated to $256^{\circ} \mathrm{C}$ and kept at this temperature for 10 minutes. Then the load of 2160 grams was applied to samples to force the melted samples out of the nozzle to measure the MFI in terms of $\mathrm{g} / 10 \mathrm{~min}$. To determine the temperature at which the treated and untreated PET samples start flowing through the nozzle of the MFI instrument, the samples were heated to $220^{\circ} \mathrm{C}$ and maintained at this temperature for 10 minutes with the nozzle closed. After 10 minutes, the load was applied, the nozzle was opened with the temperature increasing at a constant rate, and the temperature at which the sample started flowing out of the nozzle was noted for each sample.

\section{Results and Discussion}

FT-IR defines the existence of specific chemical or functional groups in the polymeric material. The combined FT-IR spectra for EG, PET, and treated PET with different mass (grams) of EG are shown in Figure 1.

The treated PET with different EG mass demonstrated the presence of new hydroxyl groups $(\mathrm{O}-\mathrm{H})$ that appeared 


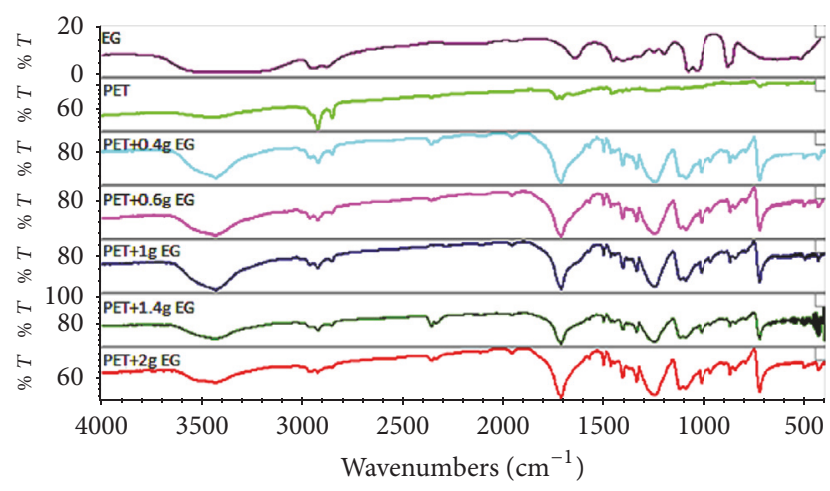

FIGURE 1: FT-IR spectra of the untreated and treated PET with different mass (grams) of ethylene glycol EG.

at wavenumber between $3500 \mathrm{~cm}^{-1}$ and $3400 \mathrm{~cm}^{-1}$ as shown in the FT-IR spectra which may contribute to the formation of inter- and intramolecular hydrogen bonds in the EG treated PET polymer. The hydroxyl groups in the treated PET polymer are contributed by EG during the interaction between the two components in the extruder. On the other hand, the nontreated PET polymer does show the presence of hydroxyl groups but with reduced intensity than the treated PET. Moreover, at wavenumber $2950 \mathrm{~cm}^{-1}$, an alkyl group (C-H stretch) appeared in the PET polymer, whereas this group was reflected with less intensity in the FT-IR spectra for the treated PET with EG, and its intensity decreases gradually with increasing EG concentration and was found to be the least for the PET treated with $2 \mathrm{~g}$ of EG. Furthermore, a carbonyl group $(\mathrm{C}=\mathrm{O}$ stretch $)$ appeared in the treated $\mathrm{PET}$ with EG at a wavenumber of $1715 \mathrm{~cm}^{-1}$, while this group is also reflected in the FT-IR spectra for the untreated PET polymer but with a lesser intensity as shown in Figure 1. Besides, an ether group (C-O-C stretch (diaryl)) is obvious for the treated PET with different EG concentrations at an approximate wavenumber of $1250 \mathrm{~cm}^{-1}$, whereas it is demonstrated at a very low intensity for the untreated PET polymer. Another band that is clearly shown in the FTIR spectra for the treated PET with EG is reflected at a wavenumber of about $1100 \mathrm{~cm}^{-1}$, while it is not shown for the untreated PET polymer. This wavenumber indicates the availability of $\mathrm{C}-\mathrm{C}$ stretch in the treated PET with different EG concentrations but not in PET polymer. In addition, the FT-IR clearly shows a band at the wavenumber of about $720 \mathrm{~cm}^{-1}$ for the treated PET with various EG concentrations, whereas it is demonstrated at a lesser intensity for the PET polymer. This peak indicates the existence of $\mathrm{CH}_{2}$ bending in treated PET with EG to a higher extent than in the untreated PET polymer. The variation in the intensity of the peaks or the presence of new peaks for the FT-IR spectra of the EG treated PET when compared to untreated PET could be due to the presence of EG in the polymeric matrix or due to the transesterification or condensation reactions of PET with EG or the formation of monomers like BHET.

Thermogravimetric analysis (TGA) was carried out to assess the thermal stability, the stages of degradation, and the moisture percentage in the sample. The TGA for the untreated PET and treated PET with 0.4, 0.6, 1, 1.4, and 2 grams of EG was carried out. The combined results of the TGA analysis for all the samples are shown in Figure 2(a). TGA readings, including initial decomposition temperature $\left(T_{\mathrm{dec}}\right)$, percent weight loss $(W \%)$, and percentage of moisture are summarized in Table 1.

The thermal degradation of polymers is a complex process and consists of initiation, propagation, and termination stages [40]. Initial decomposition temperature of the PET treated with EG as well as neat PET polymer was found to be at about $374^{\circ} \mathrm{C}$. The weight loss at $100^{\circ} \mathrm{C}$ which corresponds to the moisture content was found to be very low for all the PET samples. From the TGA test, the moisture content in the PET polymer was shown to be $0.1 \%$. On the other hand, the moisture content in the treated PET with $0.4 \mathrm{~g}$ of EG was $0 \%$. This value increased gradually with the increase in the EG concentration as shown in Table 1. The weight loss percent at the decomposition temperature was investigated for all the samples. The weight loss for the EG treated PET increased with increase in the EG mass; that is, the PET treated with $0.4 \mathrm{~g}$ of EG showed $2.59 \%$ weight loss, whereas this value rose to $5.24 \%$ for PET with $2 \mathrm{~g}$ of EG. On the contrary, the value of the weight loss percent for the neat PET polymer was found to be 0.73 , which is less compared to the PET samples treated with EG. From Figure 2(b), in the derivative thermogravimetric (DTG) analysis, the peak temperature values were found to be $437,434,436,444,448$, and $450^{\circ} \mathrm{C}$ for the PET treated with $0,0.4,0.6,1,1.4$, and 2 grams of EG, respectively.

The organic macromolecules or the low-molecular weight organic molecules that constitute the polymer matrix can withstand a particular temperature range and this forms the basis for the thermal degradation of polymers. The thermal stability of the polymers relies on the intrinsic features of the specimen and also the particular interface or interactions among the different macromolecular or molecular components of the polymeric matrix [41]. When certain lowmolecular weight materials called plasticizers are added to the polymer matrix, it results in the modification of the 3dimensional organization of the polymeric structure. Plasticizers also reduce the intermolecular forces of attraction, thereby increasing the mobility and volume of the polymeric matrix. This phenomenon is achieved by the formation of linkages in the form of hydrogen $(\mathrm{H})$ bonds between the hydroxyl groups and the polar functional groups present in the polymer and plasticizer [42].

From the TGA curves for the untreated PET and PET treated with different EG mass, it is observed that all the specimens are relatively stable in the temperature range of $25-350^{\circ} \mathrm{C}$. In addition, the percentage of moisture content in all the samples measured at about $100^{\circ} \mathrm{C}$ is almost negligible. Besides, it is clear from the graph that the TGA curves for all the samples indicate one-step degradation, where the degradation temperature $\left(T_{d}\right)$ is within the range of $370-410^{\circ} \mathrm{C}$. The weight loss for all the samples at $374^{\circ} \mathrm{C}$ is shown in Table 1. The onset thermal degradation point for all treated PET starts at $374^{\circ} \mathrm{C}$. Beyond the temperature of $374^{\circ} \mathrm{C}$, the PET/EG polymer becomes significantly degraded. Moreover, as the mass of EG increases in the PET sample, the 


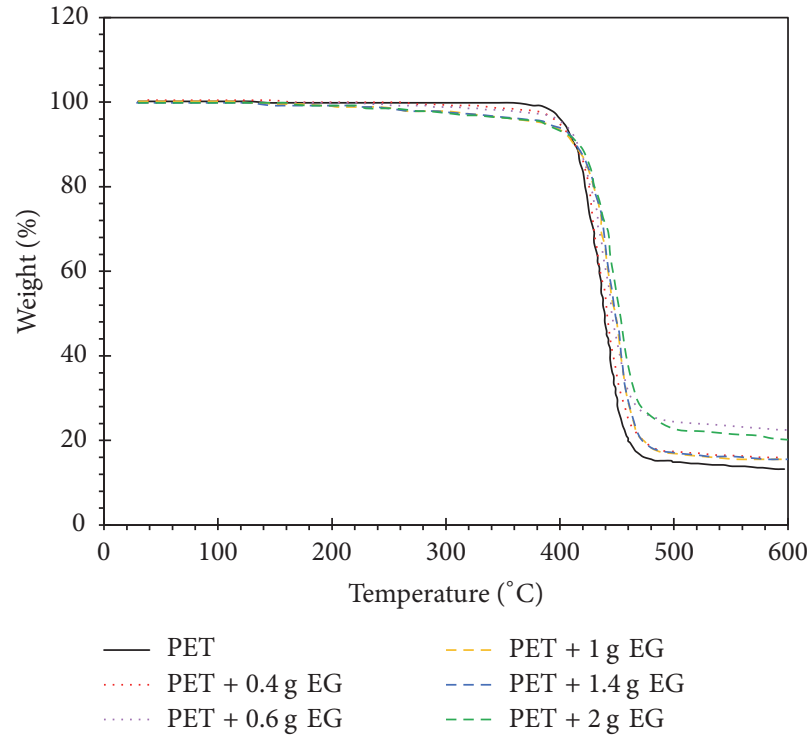

(a)

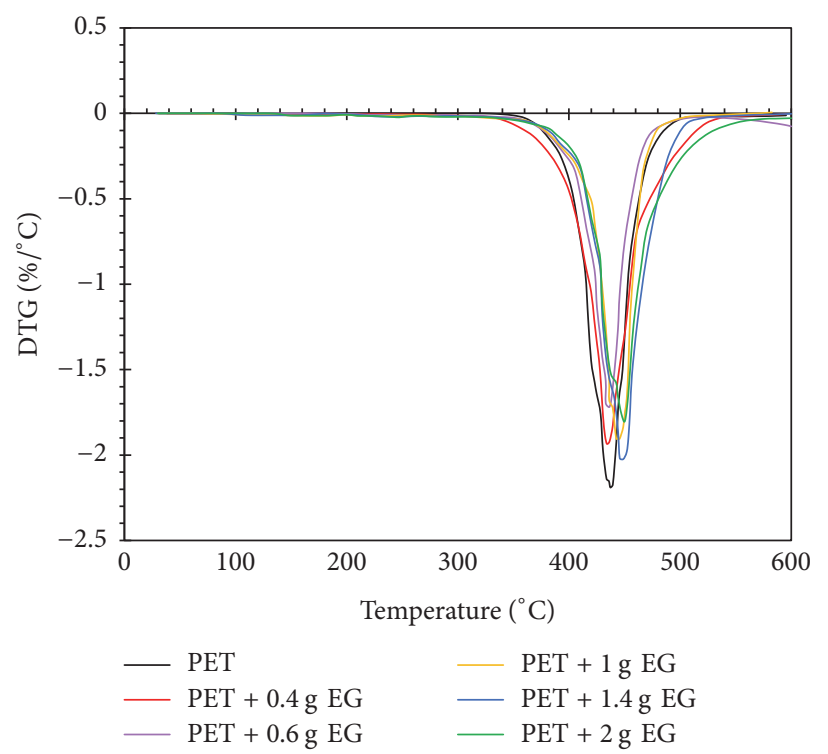

(b)

FIgure 2: (a) TGA curves and (b) DTG analysis for the untreated and EG treated PET.

TABLE 1: Total weight loss of all samples.

\begin{tabular}{|c|c|c|c|c|c|c|}
\hline Sample & $\begin{array}{c}\text { PET + 0 g } \\
\text { EG }\end{array}$ & $\begin{array}{c}\mathrm{PET}+0.4 \mathrm{~g} \\
\mathrm{EG}\end{array}$ & $\begin{array}{c}\mathrm{PET}+0.6 \mathrm{~g} \\
\mathrm{EG}\end{array}$ & $\begin{array}{l}\mathrm{PET}+1 \mathrm{~g} \\
\mathrm{EG}\end{array}$ & $\begin{array}{c}\mathrm{PET}+1.4 \mathrm{~g} \\
\mathrm{EG}\end{array}$ & $\begin{array}{c}\mathrm{PET}+2 \mathrm{~g} \\
\mathrm{EG}\end{array}$ \\
\hline $\begin{array}{l}\text { Decomposition } \\
\text { temperature }\left({ }^{\circ} \mathrm{C}\right)\end{array}$ & 374.64 & 374.71 & 374.71 & 374.71 & 374.71 & 374.71 \\
\hline$\%$ weight loss & 0.73 & 2.59 & 2.81 & 4.37 & 4.89 & 5.42 \\
\hline $\begin{array}{l}\% \text { moisture content } \\
\text { @ } 100^{\circ} \mathrm{C}\end{array}$ & 0.1 & 0 & 0.02 & 0.12 & 0.18 & 0.12 \\
\hline
\end{tabular}

weight loss increases at the temperature of $374^{\circ} \mathrm{C}$, where the weight loss percentage increased from 2.59 for PET treated with $0.4 \mathrm{~g}$ of EG to 5.42 for PET treated with $2 \mathrm{~g}$ of EG. This could be due to the volatile nature of the plasticizer at higher temperature.

Differential scanning calorimetry analysis (DSC) was carried out for all the samples to determine the melting points $\left(T_{m}\right)$ of untreated PET and the treated PET with $0.4 \mathrm{~g}$, $0.6 \mathrm{~g}, 1 \mathrm{~g}, 1.4 \mathrm{~g}$, and $2 \mathrm{~g}$ of EG. From the TGA curves, the degradation of the PET samples begins at $374^{\circ} \mathrm{C}$, beyond which there is enhanced weight loss and degradation and hence the DSC thermograms were concluded at $400^{\circ} \mathrm{C}$. The combined DSC thermograms of the PET/EG for various EG masses are shown in Figure 3. In addition, a summary of the DSC analysis results, mainly the melting point $\left(T_{m}\right)$, is shown in Table 2.

The main physical property investigated by using DSC test was the melting point of all the samples. As shown in Table 2, the melting point of PET polymer was found to be $243.49^{\circ} \mathrm{C}$. It is clear that the melting point of the treated PET with EG decreased with increase in the EG mass.

From the DSC curve, it can be seen that the relaxation in the thermal region of $230-260^{\circ} \mathrm{C}$ is triggered by the softening of the PET crystalline domains due to melting. With increase in the content of EG in the PET matrix, a shifting trend in the
DSC curve was observed as shown in Figure 3(a). This shift noticeably shows a decrease in the melting point of the treated PET with increase in EG mass, where the melting point of the treated PET decreased from $250.08^{\circ} \mathrm{C}$ to $242.33^{\circ} \mathrm{C}$ with the increase in EG mass from $0.4 \mathrm{~g}$ to $2 \mathrm{~g}$, as shown in Table 2. The DSC thermograms for the entire temperature range used in the experiment are shown in Figure 3(b). This decrease in the melting temperature might signify that the systematic compact organization of the PET molecules was reduced with the introduction of EG into the polymeric matrix. Also, it can be inferred that EG enhances the mobility of PET segments and reduces PET crystalline regions.

The mechanical properties of PET as well as the PET treated with different EG mass were investigated by nanoindentation. The maximum load applied for each nanoindentation on a sample was $10.03 \mathrm{mN}$. A total of five indentations were made on each sample. Figures 4(a)-4(f) show the loading-depth curves of PET treated with $0 \mathrm{~g}, 0.4 \mathrm{~g}, 0.6 \mathrm{~g}$, $1 \mathrm{~g}, 1.4 \mathrm{~g}$, and $2 \mathrm{~g}$ of EG, respectively. The main mechanical properties examined using the nanoindentation test were the maximum depth covered by the indenter through the sample, the hardness, and the reduced modulus of the tested samples. These results are listed in Table 3 for all samples.

It is clear from the table that the maximum depth reached by the indenter in the PET polymer without EG was found 


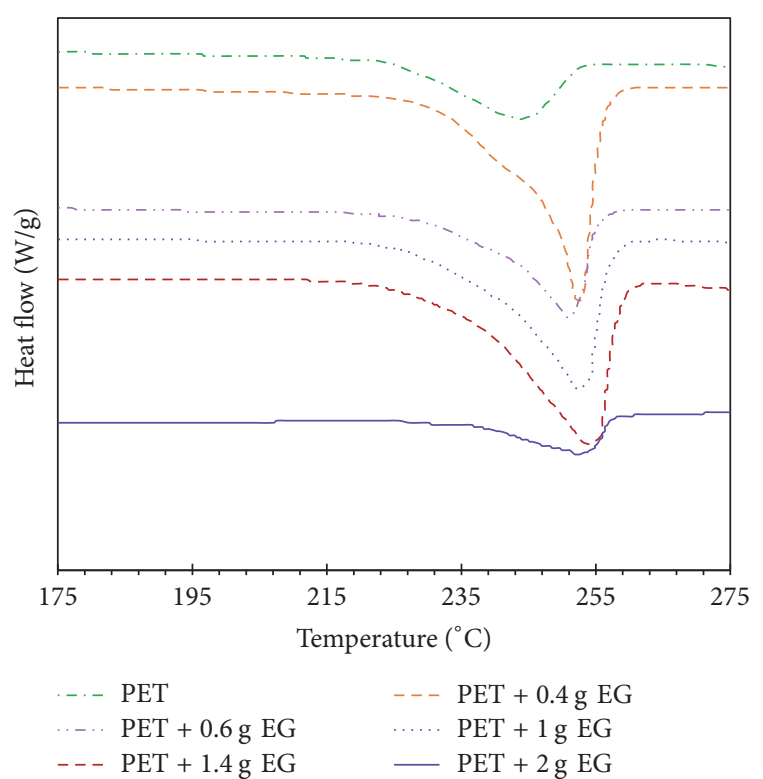

(a)

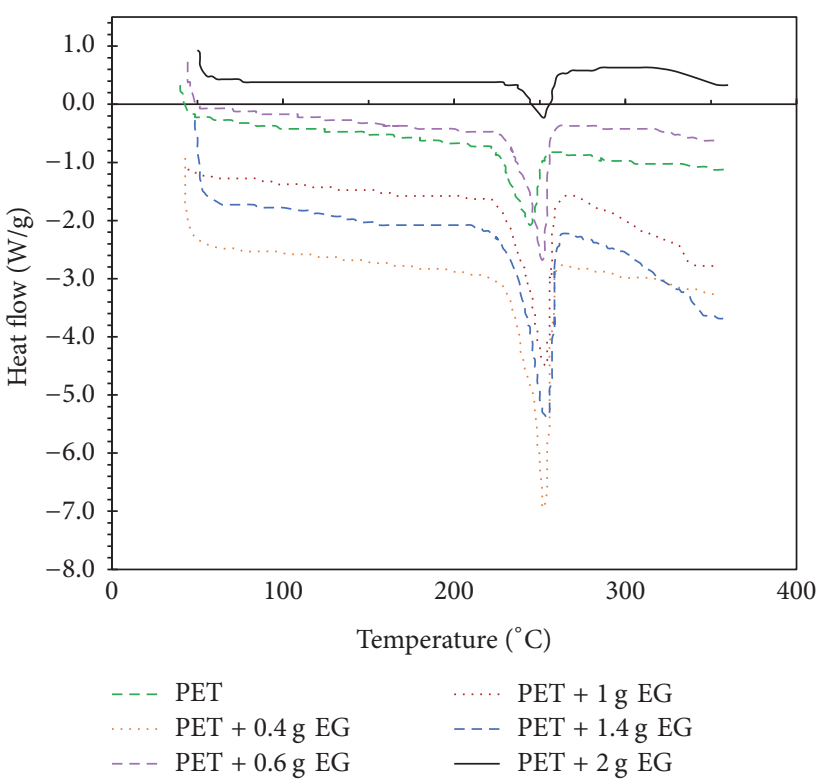

(b)

FIGURE 3: DSC curves for untreated and EG treated PET. (a) DSC for temperature range between 175 and $275^{\circ} \mathrm{C}$, and (b) DSC for the entire temperature range used in the experiment.

TABLE 2: Melting point values for all the nontreated PET and EG treated PET samples.

\begin{tabular}{|c|c|c|c|c|c|c|}
\hline Sample & PET & $\begin{array}{c}\mathrm{PET}+0.4 \mathrm{~g} \\
\mathrm{EG}\end{array}$ & $\begin{array}{l}\mathrm{PET}+0.6 \mathrm{~g} \\
\mathrm{EG}\end{array}$ & $\begin{array}{l}\mathrm{PET}+1 \mathrm{~g} \\
\mathrm{EG}\end{array}$ & $\begin{array}{l}\mathrm{PET}+1.4 \mathrm{~g} \\
\mathrm{EG}\end{array}$ & $\begin{array}{l}\mathrm{PET}+2 \mathrm{~g} \\
\mathrm{EG}\end{array}$ \\
\hline $\begin{array}{l}\text { Melting temperature } \\
\left({ }^{\circ} \mathrm{C}\right)\end{array}$ & 243.49 & 250.08 & 247.37 & 246.03 & 245.83 & 242.33 \\
\hline
\end{tabular}

to be $1043.03 \mathrm{~nm}$. On the other hand, the PET treated with EG exhibited an increase in the maximum depth attained by the indenter with increase in the EG concentration used for treatment. The maximum depth attained was found to be $1169.08 \mathrm{~nm}$ for PET treated with $0.4 \mathrm{~g}$ of ethylene glycol and $1546.05 \mathrm{~nm}$ for PET treated with $2 \mathrm{~g}$ of EG. Moreover, the hardness and reduced modulus of the PET treated with ethylene glycol showed lower values when compared to the untreated PET polymer. Furthermore, the hardness of the treated polymer showed a decreasing trend with increase in the mass of EG when compared to untreated PET polymer. The nanoindentation test showed that the hardness of PET with $0.4 \mathrm{~g}$ EG was $0.41722 \mathrm{GPa}$, while this value decreased to $0.23520 \mathrm{GPa}$ for PET treated with $2 \mathrm{~g}$ of EG. Similar to the hardness trend, the reduced modulus also showed a decreasing trend with increase in the concentration of EG. The maximum value for the reduced modulus $\left(E_{r}\right)$ was recorded to be $8.13187 \mathrm{GPa}$ for the PET without EG treatment. On the contrary, the lowest $E_{r}$ value was found to be $5.23870 \mathrm{GPa}$ for the PET treated with $2 \mathrm{~g}$ of EG. Similarly, the elastic modulus for PET without EG treatment was found to be $7.185 \mathrm{GPa}$ and the lowest elastic modulus was obtained for the PET treated with $2 \mathrm{~g}$ of EG, which was found to be 4.618 GPa.

Plasticizers are also known to influence the mechanical properties of polymers. With increase in the plasticizer content in the polymeric matrix, the tensile strength of the polymer decreases whereas the elongation period to break is increased [39]. As the EG mass in the PET was increased, the hardness as well as the reduced modulus decreased. On the other hand, the maximum depth attained by the indenter in the sample increased with the increase in EG concentration in PET. The intramolecular forces in PET were decreased by the presence of EG. Subsequently, the presence of plasticizer will also result in the reduction in the melting point of the treated PET as indicated by DSC. Low-molecular weight small molecules of EG may get implanted between the PET chains or matrix, thereby increasing the free volume and spacing, allowing the polymeric chains to slide past each other at lower temperatures.

The melt flow index of PET and PET treated with EG was measured. The results are summarized in Table 4 . From the results, it can be seen that the flow index for PET increases with increase in the mass of EG added during treatment. The flow index was $0.891 \mathrm{~g} / 10 \mathrm{~min}$ for untreated PET, whereas the flow index was 13.627 and $12.17 \mathrm{~g} / 10 \mathrm{~min}$ for PET treated with 1.4 and 2 grams of EG, respectively.

To determine the temperature at which the samples start flowing out of nozzle of the MFI instrument, the samples were heated to $220^{\circ} \mathrm{C}$ with nozzles closed followed by opening the nozzle, applying the load, and increasing the temperature at a constant rate. With increase in the mass of EG used 


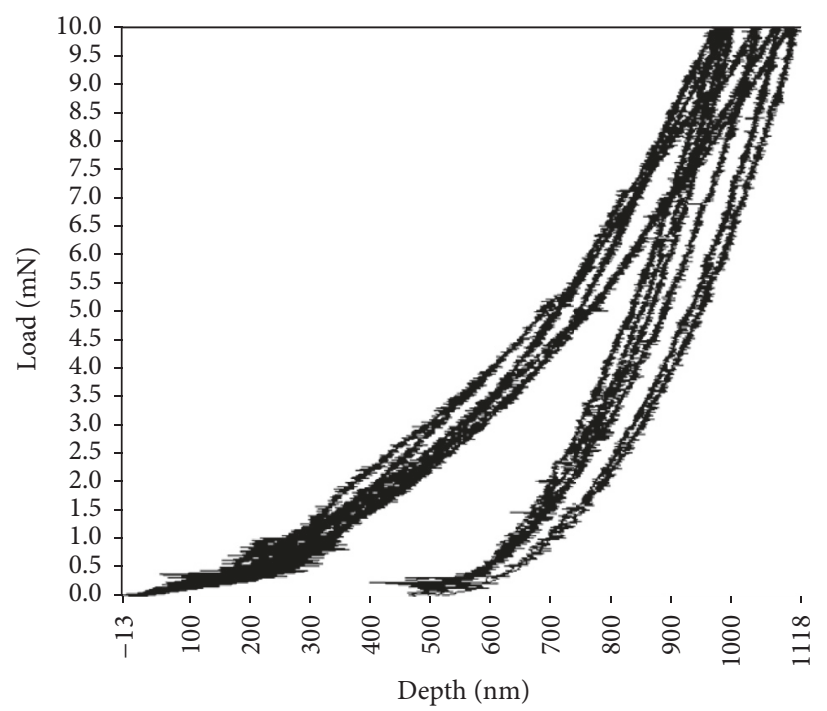

(a)

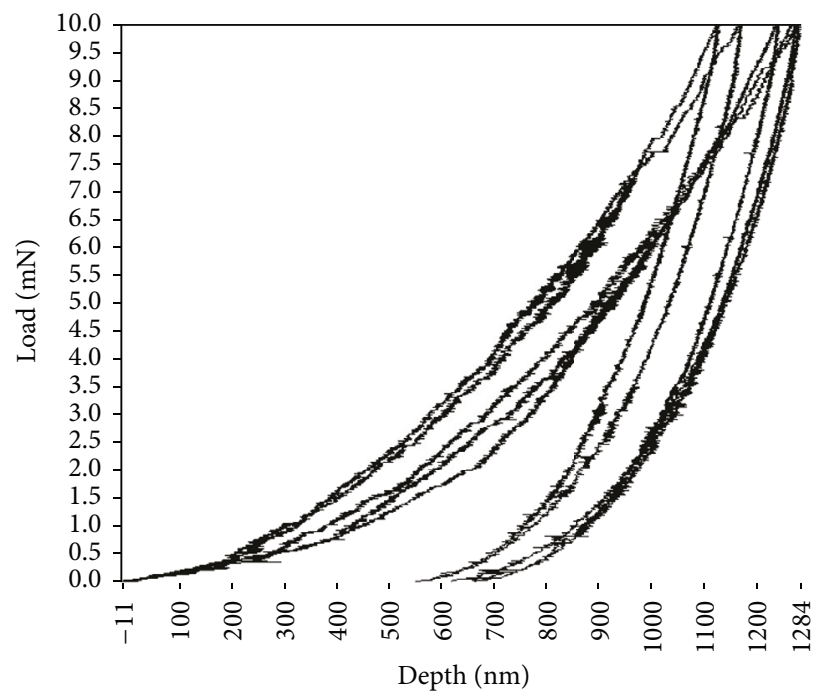

(c)

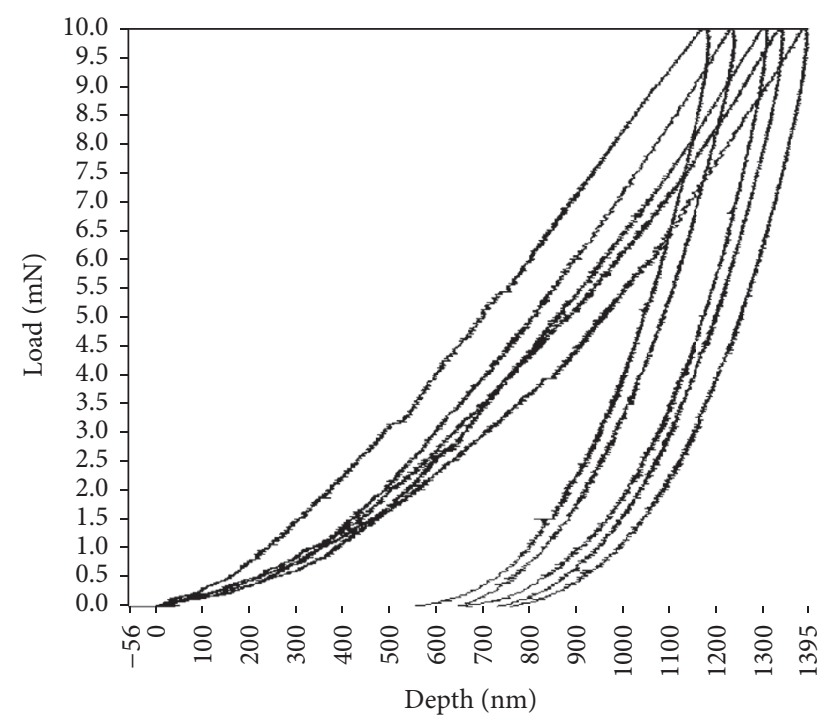

(e)

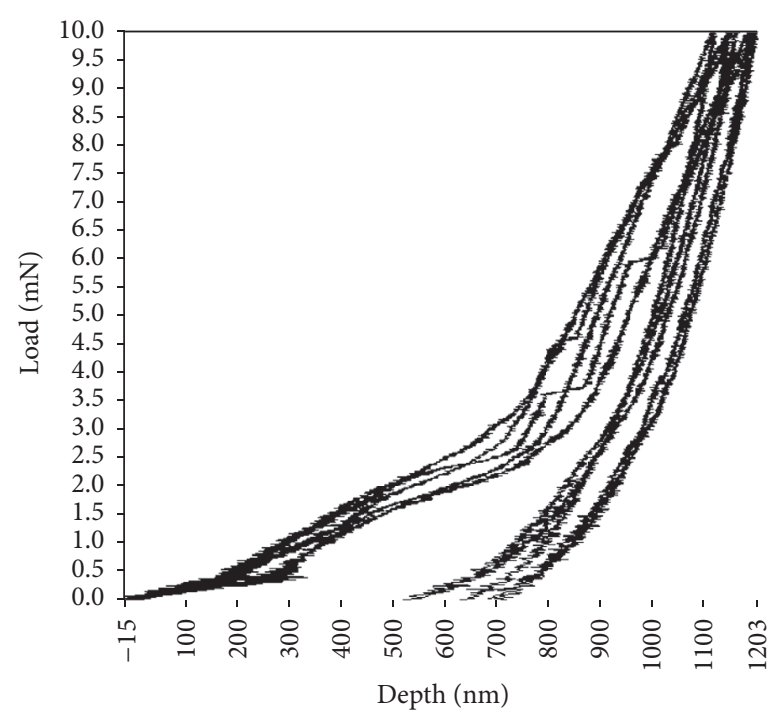

(b)

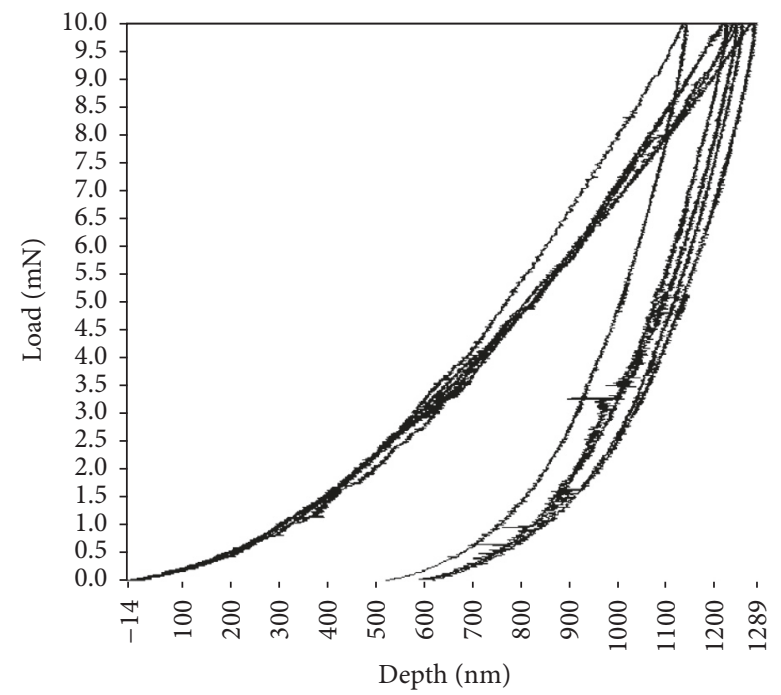

(d)

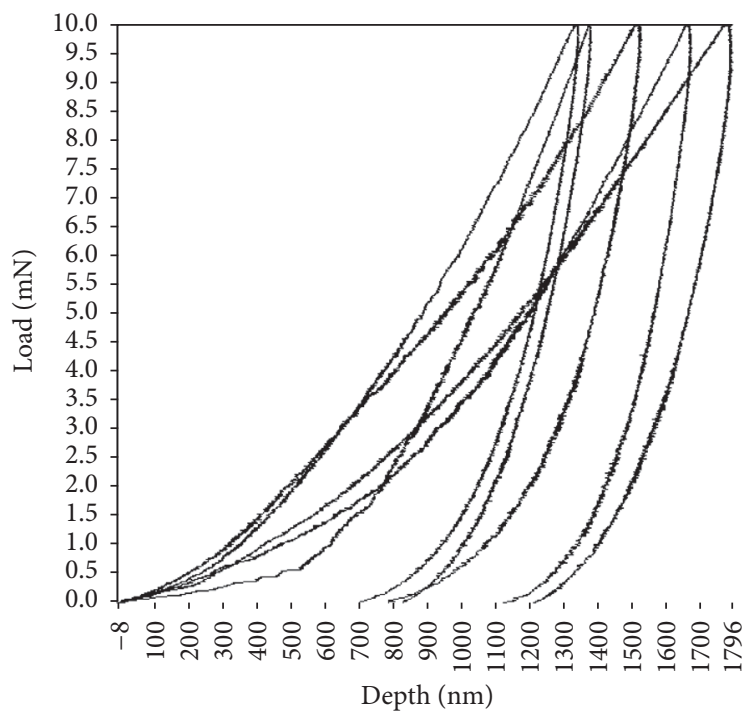

(f)

FIGURE 4: Nanoindentation graphs of PET treated with $0,0.4,0.6,1,1.4$, and 2 grams of EG, respectively. 
TABLE 3: Nanoindentation results of all samples.

\begin{tabular}{|c|c|c|c|c|c|c|}
\hline Sample & PET & $\begin{array}{c}\mathrm{PET}+0.4 \mathrm{~g} \\
\mathrm{EG}\end{array}$ & $\begin{array}{c}\mathrm{PET}+0.6 \mathrm{~g} \\
\mathrm{EG}\end{array}$ & $\begin{array}{c}\text { PET + } 1 \mathrm{~g} \\
\text { EG }\end{array}$ & $\begin{array}{c}\mathrm{PET}+1.4 \mathrm{~g} \\
\mathrm{EG}\end{array}$ & $\begin{array}{c}\mathrm{PET}+2 \mathrm{~g} \\
\mathrm{EG}\end{array}$ \\
\hline Maximum depth (nm) & 1043.03 & 1169.08 & 1221.94 & 1235.42 & 1296.2 & 1546.05 \\
\hline Hardness (GPa) & 0.57571 & 0.41722 & 0.39487 & 0.38957 & 0.35241 & 0.23520 \\
\hline Reduced modulus (GPa) & 8.13187 & 7.70008 & 6.66154 & 6.35526 & 5.92548 & 5.23871 \\
\hline Elastic modulus (GPa) & 7.185 & 6.802 & 5.879 & 5.607 & 5.226 & 4.618 \\
\hline
\end{tabular}

TABLE 4: Flow index results for untreated and EG treated PET samples.

\begin{tabular}{|c|c|c|c|c|c|c|}
\hline Sample & PET & $\begin{array}{c}\mathrm{PET}+0.4 \mathrm{~g} \\
\mathrm{EG}\end{array}$ & $\begin{array}{c}\mathrm{PET}+0.6 \mathrm{~g} \\
\mathrm{EG} \\
\end{array}$ & $\begin{array}{c}\mathrm{PET}+1 \mathrm{~g} \\
\mathrm{EG}\end{array}$ & $\begin{array}{c}\mathrm{PET}+1.4 \mathrm{~g} \\
\mathrm{EG}\end{array}$ & $\begin{array}{c}\mathrm{PET}+2 \mathrm{~g} \\
\mathrm{EG}\end{array}$ \\
\hline Flow index $(\mathrm{g} / 10 \mathrm{~min})$ & 0.891 & 2.501 & 7.329 & 7.762 & 13.627 & 12.170 \\
\hline
\end{tabular}

TABLE 5: Melt flow start temperature for the untreated and EG treated PET samples.

\begin{tabular}{|c|c|c|c|c|c|c|}
\hline Sample & PET & $\begin{array}{c}\text { PET + } 0.4 \mathrm{~g} \\
\mathrm{EG}\end{array}$ & $\begin{array}{c}\mathrm{PET}+0.6 \mathrm{~g} \\
\mathrm{EG}\end{array}$ & $\begin{array}{l}\text { PET + } 1 \mathrm{~g} \\
\mathrm{EG}\end{array}$ & $\begin{array}{c}\mathrm{PET}+1.4 \mathrm{~g} \\
\mathrm{EG}\end{array}$ & $\begin{array}{c}\mathrm{PET}+2 \mathrm{~g} \\
\mathrm{EG}\end{array}$ \\
\hline Flow start temperature $\left({ }^{\circ} \mathrm{C}\right)$ & 256 & 244.5 & 240 & 236 & 233 & 230 \\
\hline
\end{tabular}

for treating PET, the temperature at which the samples start flowing through the nozzle was decreased. The results of the flow start temperature for the treated and untreated PET samples with EG are given in Table 5.

The flow index of the treated PET has clearly shown the effect of EG concentration in the PET polymer. The melt flow index increases with increase in the EG mass but the flow start temperature decreases with increase in EG concentration. Consequently, the presence of EG resulted in less viscosity of the PET samples at lower temperatures and hence ethylene glycol plays the role of a plasticizer in the PET samples.

\section{Conclusion}

In this work, $\mathrm{PET}$ was placed inside an extruder at $260^{\circ} \mathrm{C}$ with different EG mass, allowed to react, followed by extruding the samples. The chemical, thermal, and mechanical properties as well as the flow index of the treated PET were tested using FT-IR, TGA, DSC, nanoindentation, and melt flow index. The FT-IR spectra showed that addition of EG resulted in the occurrence of new hydroxyl groups in the treated PET. The intensities of specific peaks were intensified indicating that EG had interacted with PET polymeric matrix. Furthermore, the percent weight loss at the onset of thermal degradation increased with increase in EG mass used for PET treatment as indicated by the thermogravimetric analysis. Moreover, from the DSC thermograms, it can be observed that the melting point of the treated PET decreased with increase in the mass of EG. Also, the mechanical properties were affected by the presence of EG in the PET matrix. The results of the melt flow index analysis indicated that, with increase in the concentration of EG in the PET polymer, the flow index increased and consequently caused the sample to become less viscous. It can be inferred that EG interacts with PET and plays the role of a plasticizer filling the gaps between the polymer chains. This also explains the decrease in hardness and reduced modulus with increase in EG concentration in the PET polymeric matrix. The reactive extrusion of polymers can be utilized to modulate their mechanical and thermal properties. Also, further research can be conducted by the utilization of suitable catalysts or ionic liquids to modify the properties of extruded PET.

\section{Conflicts of Interest}

The authors declare that they have no conflicts of interest.

\section{References}

[1] M. Peplow, "The plastics revolution: how chemists are pushing polymers to new limits," Nature, vol. 536, no. 7616, pp. 266-268, 2016.

[2] S. R. Shukla and A. M. Harad, "Glycolysis of polyethylene terephthalate waste fibers," Journal of Applied Polymer Science, vol. 97, no. 2, pp. 513-517, 2005.

[3] A. Stoski, M. F. Viante, C. S. Nunes, E. C. Muniz, M. L. Felsner, and C. A. P. Almeida, "Oligomer production through glycolysis of poly(ethylene terephthalate): effects of temperature and water content on reaction extent," Polymer International, vol. 65, no. 9, pp. 1024-1030, 2016.

[4] A. M. Al-Sabagh, F. Z. Yehia, A.-M. M. F. Eissa et al., "Glycolysis of poly(ethylene terephthalate) catalyzed by the Lewis base ionic liquid [Bmim] [OAc]," Industrial \& Engineering Chemistry Research, vol. 53, no. 48, pp. 18443-18451, 2014.

[5] S. R. Shukla, V. Palekar, and N. Pingale, "Zeolite catalyzed glycolysis of polyethylene terephthalate bottle waste," Journal of Applied Polymer Science, vol. 110, no. 1, pp. 501-506, 2008.

[6] R. V. Shah, V. S. Borude, and S. R. Shukla, "Recycling of PET waste using 3-amino-1-propanol by conventional or microwave irradiation and synthesis of bis-oxazin there from," Journal of Applied Polymer Science, vol. 127, no. 1, pp. 323-328, 2013.

[7] M. Khoonkari, A. H. Haghighi, Y. Sefidbakht, K. Shekoohi, and A. Ghaderian, "Chemical Recycling of PET Wastes with 
Different Catalysts,' International Journal of Polymer Science, vol. 2015, Article ID 124524, pp. 1-11, 2015.

[8] S. R. Shukla and A. M. Harad, "Aminolysis of polyethylene terephthalate waste," Polymer Degradation and Stability, vol. 91, no. 8, pp. 1850-1854, 2006.

[9] F. Chen, Q. Zhou, R. Bu, F. Yang, and W. Li, "Kinetics of poly(ethylene terephthalate) fiber glycolysis in ethylene glycol," Fibers and Polymers, vol. 16, no. 6, pp. 1213-1219, 2015.

[10] N. George and T. Kurian, "Recent developments in the chemical recycling of postconsumer poly(ethylene terephthalate) Waste," Industrial \& Engineering Chemistry Research, vol. 53, no. 37, pp. 14185-14198, 2014.

[11] Q. F. Yue, L. F. Xiao, M. L. Zhang, and X. F. Bai, "The glycolysis of poly(ethylene terephthalate) waste: Lewis acidic ionic liquids as high efficient catalysts," Polymer, vol. 5, no. 4, pp. 1258-1271, 2013.

[12] S. H. Park and S. H. Kim, "Poly (ethylene terephthalate) recycling for high value added textiles," Fashion and Textiles, vol. 1, no. 1, 2014.

[13] A. Al-Sabagh, F. Yehia, G. Eshaq, A. Rabie, and A. ElMetwally, "Greener routes for recycling of polyethylene terephthalate," Egyptian Journal of Petroleum, vol. 25, no. 1, pp. 53-64, 2016.

[14] A. Ghaderian, A. H. Haghighi, F. A. Taromi, Z. Abdeen, A. Boroomand, and S. M.-R. Taheri, "Characterization of rigid polyurethane foam prepared from recycling of PET waste," Periodica Polytechnica Chemical Engineering, vol. 59, no. 4, pp. 296-305, 2015.

[15] A. Aguado, L. Martínez, L. Becerra et al., "Chemical depolymerisation of PET complex waste: Hydrolysis vs. glycolysis," Journal of Material Cycles and Waste Management, vol. 16, no. 2, pp. 201-210, 2014.

[16] L. Bartolome, M. Imran, B. Gyoo, W. A, and D. Hyun, "Recent Developments in the Chemical Recycling of PET," in Material Recycling - Trends and Perspectives, pp. 10-5772, InTech, 2012.

[17] A. Koç, "Studying the utilization of plastic waste by chemical recycling method," Open Journal of Applied Sciences, vol. 3, no. 7, pp. 413-420, 2013.

[18] N. S. Todorov, M. F. Radenkov, and D. D. Todorova, "Utilization of crude glycerol and waste polyethylene terephthalate for production of alkyd resins," Journal of Chemical Technology and Metallurgy, vol. 50, no. 3, pp. 240-248, 2015.

[19] L. Zhang, J. Gao, J. Zou, and F. Yi, "Hydrolysis of poly(ethylene terephthalate) waste bottles in the presence of dual functional phase transfer catalysts," Journal of Applied Polymer Science, vol. 130, no. 4, pp. 2790-2795, 2013.

[20] J. Chen, J. Lv, Y. Ji et al., "Alcoholysis of PET to produce dioctyl terephthalate by isooctyl alcohol with ionic liquid as cosolvent," Polymer Degradation and Stability, vol. 107, pp. 178-183, 2014.

[21] H. Kurokawa, M.-A. Ohshima, K. Sugiyama, and H. Miura, "Methanolysis of polyethylene terephthalate (PET) in the presence of aluminium tiisopropoxide catalyst to form dimethyl terephthalate and ethylene glycol," Polymer Degradation and Stability, vol. 79, no. 3, pp. 529-533, 2003.

[22] F. Liu, X. Cui, Z. Li, and X. Ge, in Proceedings of the 5th ISFR, pp. 272-276, Chengdu, China, 2009.

[23] C. N. Hoang and Y. H. Dang, "Aminolysis of poly(ethylene terephthalate) waste with ethylenediamine and characterization of a,u-diamine products," Polymer Degradation and Stability, vol. 98, no. 3, pp. 697-708, 2013.

[24] N. E. Kamber, Y. Tsujii, K. Keets et al., “The Depolymerization of Poly(ethylene terephthalate) (PET) Using N-Heterocyclic
Carbenes from Ionic Liquids," Journal of Chemical Education, vol. 87, no. 5, pp. 519-521, 2010.

[25] M. Imran, B.-K. Kim, M. Han, B. G. Cho, and D. H. Kim, "Suband supercritical glycolysis of polyethylene terephthalate (PET) into the monomer bis(2-hydroxyethyl) terephthalate (BHET)," Polymer Degradation and Stability, vol. 95, no. 9, pp. 1685-1693, 2010.

[26] H. Wang, Y. Liu, Z. Li, X. Zhang, S. Zhang, and Y. Zhang, "Glycolysis of poly(ethylene terephthalate) catalyzed by ionic liquids," European Polymer Journal, vol. 45, no. 5, pp. 1535-1544, 2009.

[27] H. Yue, Y. Zhao, X. Ma, and J. Gong, "Ethylene glycol: properties, synthesis, and applications," Chemical Society Reviews, vol. 41, no. 11, p. 4218, 2012.

[28] S. K. Kanojiya, G. Shukla, S. Sharma et al., "Hydrogenation of Styrene Oxide to 2-Phenylethanol over Nanocrystalline Ni Prepared by Ethylene Glycol Reduction Method," International Journal of Chemical Engineering, vol. 2014, Article ID 406939, 2014.

[29] A. N. A. S. A. A. Syariffuddeen, "Glycolysis of Poly (Ethylene Terephthalate) (PET) waste under conventional convectionconductive glycolysis," International Journal of Engineering Research and Technology, 2012.

[30] V. Sharma, P. Shrivastava, and D. D. Agarwal, "Degradation of PET-bottles to monohydroxyethyl terephthalate (MHT) using ethylene glycol and hydrotalcite," Journal of Polymer Research, vol. 22, no. 12, article no. 241, pp. 1-10, 2015.

[31] K. Ertas and G. Güçlü, "Alkyd resins synthesized from glycolysis products of waste PET," Polymer-Plastics Technology and Engineering, vol. 44, no. 5, pp. 783-794, 2005.

[32] K. Gotoh, A. Yasukawa, and Y. Kobayashi, "Wettability characteristics of poly(ethylene terephthalate) films treated by atmospheric pressure plasma and ultraviolet excimer light," Polymer Journal, vol. 43, no. 6, pp. 545-551, 2011.

[33] S. Makkam and W. Harnnarongchai, "Rheological and mechanical properties of recycled PET modified BY reactive extrusion," in Proceedings of the Eco-Energy and Materials Science and Engineering, EMSES 2014, pp. 547-553, Thailand, December 2013.

[34] N. Dardmeh, A. Khosrowshahi, H. Almasi, and M. Zandi, "Study on Effect of the Polyethylene Terephthalate/Nanoclay Nanocomposite Film on the Migration of Terephthalic Acid into the Yoghurt Drinks Simulant," Journal of Food Process Engineering, vol. 40, no. 1, Article ID e12324, 2017.

[35] Y. Zhu, Y. Wang, L. Sha, and J. Zhao, "Preparation of antimicrobial fabric using magnesium-based PET masterbatch," Applied Surface Science, vol. 425, pp. 1101-1110, 2017.

[36] M. Niu, X. Wang, Y. Yang et al., "The structure of microencapsulated carbon microspheres and its flame retardancy in poly(ethylene terephthalate)," Progress in Organic Coatings, vol. 95, pp. 79-84, 2016.

[37] A. Al-Mulla, "Enthalpy-entropy compensation in polyester degradation reactions," International Journal of Chemical Engineering, Article ID 782346, 2012.

[38] W. D. Q. Lamas, J. C. F. Palau, and J. R. D. Camargo, "Waste materials co-processing in cement industry: Ecological efficiency of waste reuse," Renewable \& Sustainable Energy Reviews, vol. 19, pp. 200-207, 2013.

[39] R. Baidya, S. K. Ghosh, and U. V. Parlikar, "Co-processing of Industrial Waste in Cement Kiln - A Robust System for Material and Energy Recovery," Procedia Environmental Sciences, vol. 31, pp. 309-317, 2016. 
[40] F. Welle, "Twenty years of PET bottle to bottle recycling-an overview," Resources, Conservation \& Recycling, vol. 55, no. 11, pp. 865-875, 2011.

[41] M. Mohsin, A. Hossin, and Y. Haik, "Thermal and mechanical properties of poly(vinyl alcohol) plasticized with glycerol," Journal of Applied Polymer Science, vol. 122, no. 5, pp. 3102-3109, 2011.

[42] M. Mohsin, A. Hossin, and Y. Haik, "Thermomechanical properties of poly(vinyl alcohol) plasticized with varying ratios of sorbitol," Materials Science and Engineering: A Structural Materials: Properties, Microstructure and Processing, vol. 528, no. 3, pp. 925-930, 2011. 


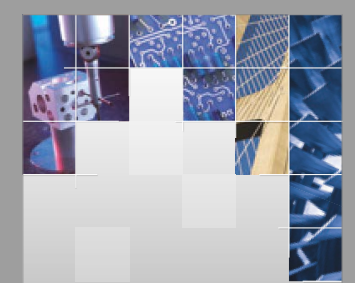

\section{Enfincering}
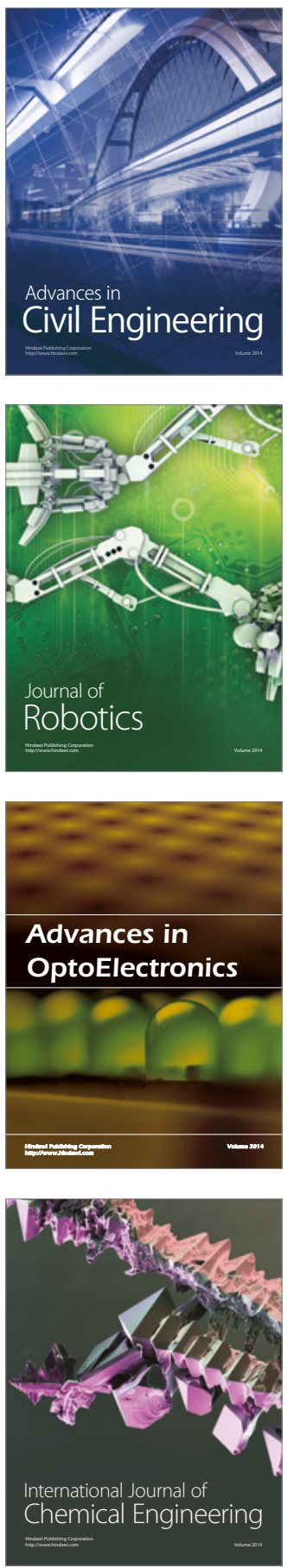

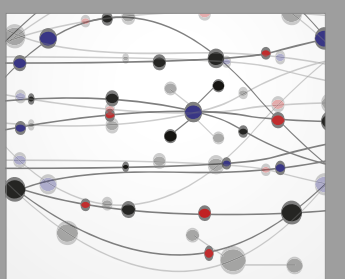

The Scientific World Journal

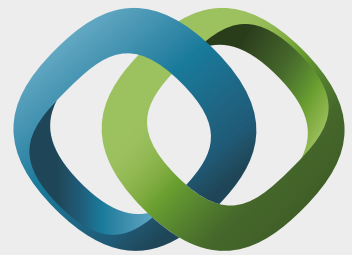

\section{Hindawi}

Submit your manuscripts at

https://www.hindawi.com
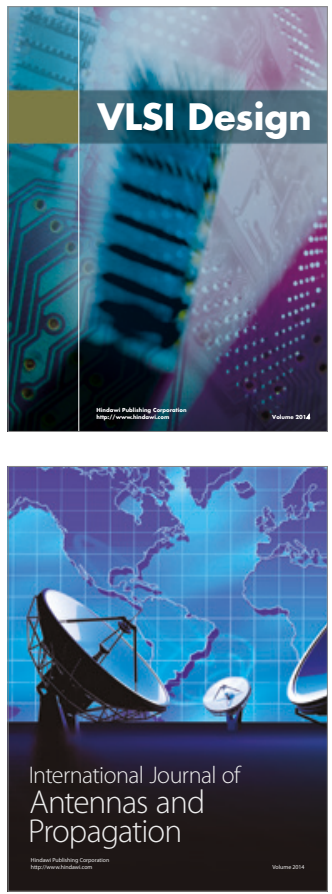

\section{Rotating}

Machinery
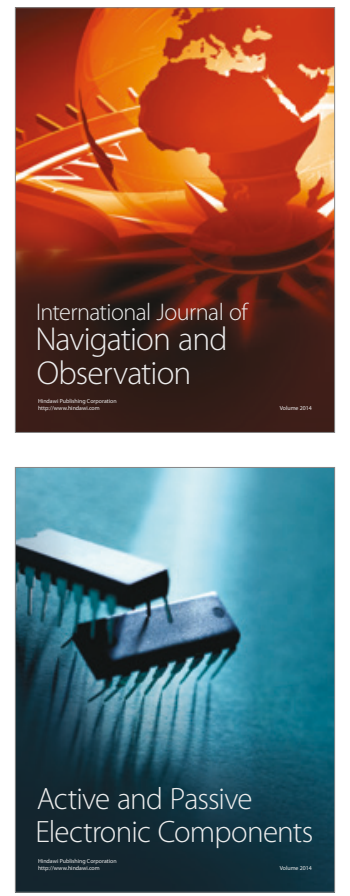
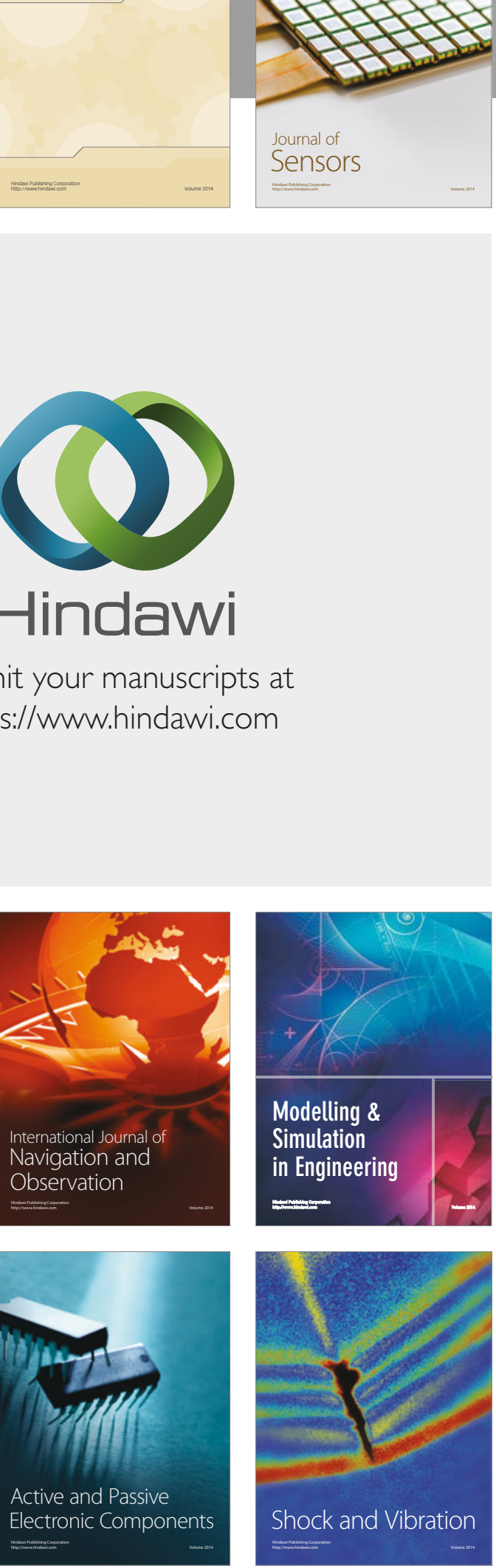
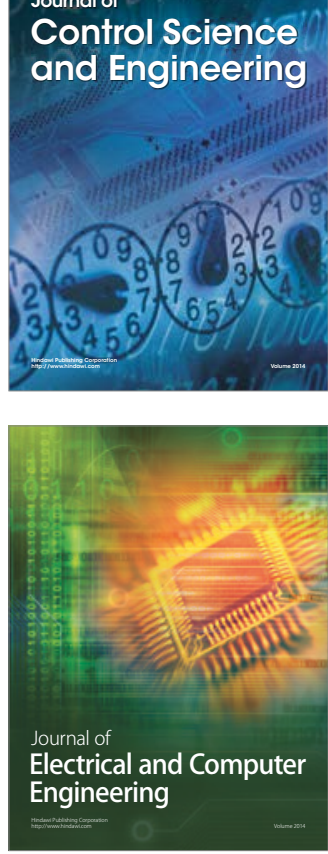

Distributed

Journal of

Control Science

and Engineering
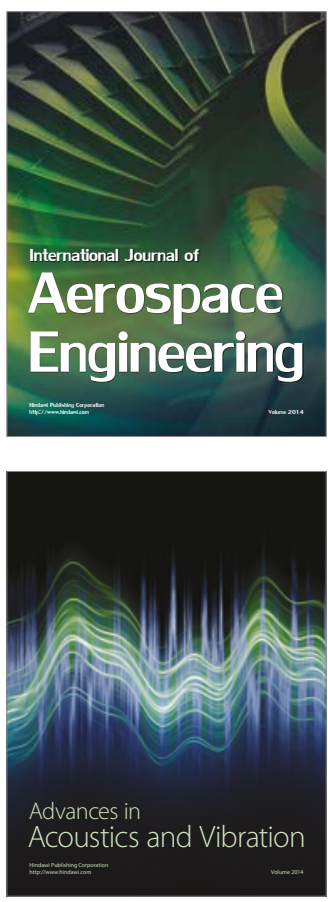

Sensor Networks 